\title{
The Bronchodilating herbs used in the treatment of COVID-19: A Review
}

\author{
Review Article
}

\section{Vadivelan $\mathbf{S}^{1 *}$, Sarojini T ${ }^{2}$, Kirubhakaran S $\mathbf{M}^{3}$, Mathukumar $\mathrm{S}^{4}$}

1. Lecturer, Department of Maruthuvam, 2. Lecturer, Department of Udalthathuvam, 3. Reader, Department of Sattam Sarntha Maruthuvamum Nanju Maruthuvamum, 4. Principal, Sri Sairam Siddha Medical College and Research Centre, Chennai.

\begin{abstract}
Nowadays, covid_19(SARS_CoV_2) intimidating the world. This disease is spreading by contact with affected droplets. Some of the affected persons are asymptomatic, majority of people suffer from mild illness, meanwhile few were affected, some severe acute respiratory distress (pneumonia) and multi organs dysfunction like Pulmonary oedema, Cardiac failure, Renal failure. Currently doctors and peoples use some spices herb (basil, clove, black pepper, turmeric, garlic, ginger, ajwain , cumin) to prevent and reduce the corona virus infection. Most of these are Bronchodilator herbs. These drugs dilate the respiratory airway and allow more volume of atmospheric air to enter the lungs. Therefore a large amount of oxygen goes into the lungs and dissolves in the respiratory membrane. Furthur more, it's transported through the blood and carried to main organs of the body. So this review article reveals Bronchodilator herbs can reduce the risk factors and prevent the respiratory distress symptoms in covid_19 (SARS_CoV_2) patients.
\end{abstract}

Key Words: Bronchodilator, Spices herb, Respiratory distress, Increased oxygen diffusion, Siddha medicine, Supportive therapy.

\section{Introduction}

The covid-19 disease is caused by SARSCOV-2 virus. Under the family coronaviridae(1).It is a positive standard RNA virus that was first reported in Wuhan city, china. This virus usually affect mammals and birds. SARS-COV-2 Virus transmitted by close contact with affected persons and spread through contact droplets (sneeze, cough etc..) Until now, prenatal communication has not discovered but Can spread via the breast milk(32).Covid-19 Symptoms vary from patient to patient. Fever, Cough, Shortness of breath, Malaise, Sore throat, Acute respiratory injury (ARDS, pneumonia),Acute renal injury, Haemoptysis, Increased respiratory secretion, Septic shock, Gastrointestinal Symptoms (nausea, vomiting, diarrhoea etc..)(1,32). From this, respiratory distress is the primary reason for create critical situation. In this state, Bronchodilators are may be the right choice to prevent this worst condition. Siddha medicine is an ancient and popular medicational system in india. This medicinal system is based on herbs, metals and animal products. Lot of spice herbs present in herbal kingdom. Spice herbs plays key role in this medication, they are easily available and harmless also. Most of the spice herbs

\section{* Corresponding Author:}

\section{Vadivelan S}

Lecturer, Department of Maruthuvam,

Sri Sairam Siddha Medical College and Research centre, Chennai-44

Tamilnadu. India

Email Id: vadivelan@sairamsiddha.edu.in have Bronchodilator effects. In which alkaloids are responsible for bronchodilating effect(33). siddha system of medication following the quote" Unavae marunthu Marunthae unavu(Let food be thy medicine and Medicine be thy food) ". Most of the south Indian peoples use the spices herb in their food. Fresh and natural healthy foods to prevent and protect our body from any kind of diseases. According to Govt of IndiaAYUSH guidelines, the food chart provided by them contains the spices herbs which we have selected for our study. Not all the spices have bronchodilating activity, only few spices herbs possesses the bronchdilating action. (34)

Aim

According to siddhars quote "Unavae marunthu Marunthae unavu (Let food be thy maedicine and Medicine be thy food)" is the aim of this review to express Spices added food is the best medicine for covid -19 affected patients and also this study will be helpful material for covid-19 related future researchers.

\section{Materials and methods}

As per all the information so far provided was collected from the databases like Google scholar, Pubmed, Web of science and so on..We have presented this article and our study provided the links in the reference part which shows that the selected spices herbs posses the bronchodilator activity.

\section{Bronchodilators}

Bronchodilators are the chief and perfect therapy for airway obstructive diseases. 
Thebronchodilator is a materi 1 that relax the bronchi and bronchioles, down resistance in the bronchial pathway and rise the flow of air in to the lungs. Natural bronchodilators obviously present in our body, sometimes may be taken as therapeutically for medication of breathing distress (33).Bronchodilators are classified into 3types. B(2)-adrenoceptor (AR) agonist, muscarinic receptor, antagonist xanthines.It can be helped as separately or combination(2). Physiologically, bronchial smooth muscular tone is managed by the parasympathetic nervous system via cholinergic and non -cholinergic innervation. Neurotransmitter acetylcholine involved in this nervous innervation. Currently accepted that exaggerated vagus nerve action plays important role in airway obstruction(3)

\section{Spice herbs}

Culinary herbs and spices have been vastly analysed in many countries because of their advantageous functions on human health (18). In this review article listed currently used some spice herbs.

\section{Black pepper}

- Botanical name: piper nigrum Linn

- Family: piperaceae

- Black pepper commonly called as "King of spices" or "black gold". The fruit of pepper have rich in medicinal properties. It is added in many cough syrups as it has antittusive and bronchodilator effects (30). Piper nigrum act as immunomodulator(4). Evaluation on black pepper, let out the bronchodilatory effect was mediated through ca++ channel blackade and phosphodiesterase (PDE)inhibitor alike effect, which may clarify its clinical significance in bronchial disorders(5).

\section{Cardamom}

- Botanical name: Elettaria cardamom Linn

- Family: Zingiberaceae

- Cardamom is a highly aromatic herb, usually called as "queen of spices". It has lot of medicinal values, especially it relax the bronchial portions. Research on cardamom shows, bronchodilatory action mediated via ca+t antagonist procedure. Which gives sound background for it's medicinal utilize in respiratory diseases(6).In corona virus (covid -19)affected cases, an intake of cardamom boost the immune system(7). A study by Sharma $\mathrm{S}$ et al in 2011that,oil extract of Elettaria cardamom seeds, in doses of 175 microliters/ $\mathrm{kg}$ and 280 microliters $/ \mathrm{kg}$ were start to decrease the inflammation(8).

\section{Clove}

- Botanical name: Syzygium aromaticum Linn

- Family: Myrrtaceae

- Syzygium aromaticum.L name implies it's characteristics. Cloves are aroma filled,dried, unopened flower bud. It have extreme fragrance and burning taste sense. It is a main spice utilized in cuisines of Russia, India, Greece, Scandinavia and china. Experimental studies on animals suggested that, eugenol react as strong bronchodilator and anti inflammatory medium for the medication of allergic respiratory diseases. An oral administration of $40 \mathrm{mg} /$ $\mathrm{kg}$ or $80 \mathrm{~g} / \mathrm{kg}$ of eugenol notably defeated the number of entire inflammatory cells and eosinophils(10). Clove has strong antiviral property, Eugenin seprated from clove buds, it exhibits antiviral action at concentration of $10 \mathrm{microgram} / \mathrm{ml}(9)$. Eugenol is the prime element of cloves volatile oil, It has potent anti inflammatory role. In animal studies, it had anti inflammatory action similar to that indomethacin at $0.05 \mathrm{and} 0.2 \mathrm{ml} / \mathrm{kg}$ doses and etodolac at 0.025 and $0.1 \mathrm{ml} / \mathrm{kgdoses}[9]$. Eugenol decrease the hyperthermia, same as antipyretic drug acetaminophen(9).

\section{Ajwain}

- Botanical name: Tracyspermum ammi Linn

- Family: Apiaceae

- Ajwain is seed like and highly fragrance fruit. It has bronchodilatory, antiviral, anti inflammatory, antifungal, antittusive and antimicrobial actions. TheTotal Alcoholic Extract(TAE) and Total Aqueous Extract (TAQ) from the ammi seeds, release an outstanding anti inflammatory power(15). The bronchodilatory actions of Ajwain decoction extract was investigated in successive trials. These trials elicit that, Ajwain extract has excellent bronchodillatory action on asthmatic airtract compared to the action of theophylline (16). An Invitro assessment was performed on the methanolic extract of Ajwain which expressed noteworthy antiviral activity results on Hepatitis $\mathrm{C}$ virus(HCV) protease(16).

\section{Cumin}

- Botanical name:Cuminum Cyminum Linn.

- Family: Apiaceae

- Cumin seeds have distinctive aroma and flavour. It as chief aroma properties are Cuminaldehyde and cuminicalcohol (17). Mohammad B et al observed that, cumin plant extract and codeine were tested on guinea pigs, that results indicate cumin has antittusive effect due to it's bronchodilatory property (14). Multiple pharmacological functions have been notified, for the extracts and essential oil from cumin herb, together with, anti inflammatory, antittusive, antimicrobial and smooth muscle relaxant effects(bronchodilation)(14).Alcoholic extract and essential oil from cumin has indications of antimicrobial activity to klebsiella pneumoniae(15).

\section{Garlic}

- Botanical name: Allium sativum Linn

- Family: Lilliaceae

- Garlic is a Bulbo perennial spice . Badreddine F et al described that, Allium sativum $L$ aqueous extract on rat, significantly increase the relaxation of bronchial smooth muscle (bronchodilation) and prevent the symptoms of high altitude respiratory distress(12). Wendy $\mathrm{P}$ et al represent that, Allium Sativum bulb aqueous extract (ASBAE) may reduce, tachypnea, in horse affected from recurrent airway obstruction 
(13).It has antiviral, antimicrobial and expectorant effects. Due to its medicinal properties,garlic added herbal preparations are used in whooping cough and other respiratory issues (19).The outcome of investigation on garlic -based time- released tablet "Allicor " may advised for ARD(Acute respiratory distress) in children(20). Many research results, proved that garlic and it's sulfuric components has immunomodulatory and antiviral actions against HIV, Herpes simplex type $1 \& 2$, Coxsackie virus, Influenza(21).

\section{Ginger}

- Botanical name: Zingiber Officinale Rosc

- Family: Zingiberaceae

- Ginger is a medicinal valued rhizome. It's active materials increases the bronchodilation by changing intracellular $\mathrm{ca}++$ in bronchial smooth muscle (22). Thetherapeutic values of ginger are mostly developed by shogaol and gingerol. Shogaol is more efficient than gingerol and it has antittusive effect(23).In vitro assay represent that ginger has effective immunomodulatory, antiviral and antimicrobial action(23). Allicin is an energetic element present in Zingiber officinale. It has antiinflammatory cytokinesis and antiviral agents to influenza $\mathrm{A}(\mathrm{H} 1 \mathrm{~N} 1)(31)$.

\section{Turmeric}

- Botanical name:Curcuma Longa Linn

- Family: Zingiberaceae

- Turmeric is commonly called as "Indian saffron". Huge studies have submitted that, maximum of the turmeric actions are due to Curcumin. Kohli.k et al have studied on various animals, that curcumin in a doses of $100-200 \mathrm{mg} / \mathrm{kg}$ can reduce the allergic respiratory inflammation by suppress the action of inflammatory protein NF kB (nuclear factor kappa B) (25). Ram A et al, in 2003 analysed, the efficacy of Curcumin on airway hyper responsiveness in guinea pigs are investigated by plethysmography, it crucially dilate the Ovalbumin-induced airway narrowing and hyperactivity in guinea pigs by bronchodilating effect(24).

\section{Mint}

- Botanical name: Mentha piperita Linn

- Family: Lamiaceae

- The peppermint has a chief element menthol component. It is the key material of cough tonics and ointments like vaporub. It is also used in pediatric seasonal cold and cough (26). Mint oil is obtained by steam distillation method. Essential oils (Eos) are administered via many ways such as oral (e.g peppermint oil), inhalation (e.g eucalyptus oil) and transdermal way(e.g rosemary oil)(11). Essential oils (Eos) possess wide range of pharmacological effects like bronchodilator, mucolytic, antiviral, antiinflammatory(11). Peppermint vapour was helped as an inhalant for bronchial congestion(26). Mint oil mixed tea was a best medication to treat cough, bronchitis, throat and oral mucosal inflammation because of its capacity to trigger laryngeal cold receptors (27).

\section{Basil}

- Botanical name : Ocimum basilicumLinn

- Family: Lamiaceae

- It is a highly used medicinal and culinary herb in india. Aqueous extract or ethanolic extract of tulsi doses from $300 \mathrm{mg} /$ day to $10 \mathrm{~g} /$ day, shoot up the natural killer cells and $T_{-}$helper cells in adults and also raise the immune resistant to viral infections (28). The Aqueous-methanolic extract of Ocimum basilicum was studied for it's bronchodilator action to be mediated via ca++ channel blockers exert respiratory smooth muscle relaxant activities in hyper reactivity of airway(29).

\section{Discussion}

In the current scenario, all over the world waiting for potential and proper treatment in COVID-19. Till date, no definite drug has been discovered. From the reviews of past and present database collections, spices have bronchodilatory effect, which also have anti inflammatory, immunomodulatory, anti pyretic, antiviral, antimicrobial and antittusive effects. In covid-19 cases, bronchial way obstruction and inflammation are the main causes to create the emergency and critical situation. bronchodilation is the best way to reduce the risk in covid-19cases. When we intake the spice herbs, in which bronchodilation effect releifs the bronchial spasm and stagnated bronchial fluids. Automatically bronchial tree allows the entry of more atmospheric air. It leads to normalise the pulmonary ventilation and oxygen diffusion in respiratory membrane. So diffused oxygen enters the blood stream and reach the vital organs in our body. It may reduce the threatening symptoms in covid cases.

\section{Conclusion}

From this review article concludes, bronchodilating spice herbs may recommended, the best supportive therapy for mild to moderate covid cases. Apart from these bronchodilating effect, it has lots of pharmacological effects. It may also help to reduce the co-symptoms of covid _19 disease. It's necessary to take the preventive measures like wearing mask, gloves, maintain isolation and social distancing. This study will do a lot of benefits for research article that explore this theme in the future.

\section{References}

1. Albaraa A Millibari. Current Situation of Coronaviris Disease (COVID-19) ReviewArticle . Health Science Journal. August 03,2020;sp.Iss 1:005.DOI:10.36648/1791-809X.S1.005.

2. Mario Coazzola, Clive P.Page, Luigino Calzetta, Maria Gabriella Matera. Pharmacology and Therapeutics of Bronchodilators. Pharmacological R e v i e w s . a s p e t jo u r n a $1 \mathrm{~s}$. J u 1 y 2012;64(3):450-504.doi:10.1124/pr.111.004580. 
3. Matera.M.G, Page.C.P, Calzetta.L, Rogliani.P, Cazzola.M. Pharmocology and Therapeutics of Bronchodilators Revisited. Pharmacological Reviews.January,2020;72(1):218-252.DOI:10.1124/ pr.119.018150.

4. Hammouti.B,Dahmani.M,Yahyi.A,Ettouhami.A,Me ssali.M,Asehraou.A,Bouyanzer.A,warad.I,Touzani. R. Black Pepper, the "king of spices": Chemical Composition to Applications. Arabian Journal of Chemical and Environmental Research.January,2019;vol-6Issue-1:12-56.

5. Abdul Rehman, Malik Hassan Mehmood Raja Jawad, Anwar ul Hassan Gilani, Maimoona Ilyas, Bina Shaheen Siddiqui, Mansoor Ahmed. Potential of Black Pepper as a Functional Food for Treatment for Airways Disorders . Journal of Functional Foods. December,2015;19 part A:126-140. https:// doi.org/10.1016/j.jff.2015.09.006.

6. Arif ullah Khan, Qaiser Janeen Khan, Anwar Hassan Gilani. Pharmacological basis for the medical use of cardamom in asthma. Bangladesh $\mathrm{J}$ o u r n a 1

o f

Pharmacology.June,2011;6(no-1):34-37.DOI:10.33 29/bjp.v6i1.8133.

7. Saad S R Al-Janaby, Ali M.A. Al-Kufaishi, Hadeel Alaa Al-rubaei, Noor J.T. Al-Musawi. Healthy Effects of Cardamom In The Mammalian: A R e vi e w. P 1 a n t September,2020;20(no-2):9073-9077.

8. Shveta Sharma, Jagmohan Sharma, Gurpreet Kaur. Therapeutic Uses of Elettaria cardomum Linn . International Journal of Drug Formulation and Research. December,2011;vol-2 Issue-6:102-108.

9. Parlee Milind Khanna Deepa. Clove: A Champion Spice. International Journal of Research in Ayurveda $\& \quad$ Pharmacy. JanuaryFebruary2011;2(1):47-54.

10. Campos Leona Maciele, Trixeira Oliveira, Cerqueira-Lima Ana Tereza, Costa Ryan Santos, Carneiro Ramires Cana Brazil, Silva Darizy Flavi, Barrett Mauricio Lima, Pontes-de-Carvalho Lain Carlos , Alcantatara-Neves Neuss and Figueiredo Camila Alexandrina . Antiasthmatic Effect of Eugenol (4-Allyl-Methoxyophenol)Mediated by Both Bronchodilator and Immunomodulatory Properties . Journal of Pharmacy and Pharmacology. January, 2014;2:38-49

11. Gyorgyi Horvath and Mamilla ACS. Essential oils in the treatment of respiratory tract diseases highlighting their role in bacterial infections and their anti-inflammatory action: a review. Flavour a $\mathrm{nd}$ Frag r a n c e Journal.May,2015;30:331-341.https://doi.org/ 10.1002/ffj.3252.

12. Badreddine Fehri, Mueen K.K. Ahmed and JeanMarc Aiache. The relaxant effect induced by Allium Sativum.L. bulb aqueous extract on rat isolated $\mathrm{t} \mathrm{rach}$ e a $\mathrm{P} \mathrm{h}$ a r m a c o g n o s y Magazine.January,2011;7(25):14-18.DOI:10.4103/0 973-1296.75879.

13. Wendy Pearson, Armen Charcha, Dyanne Brewer, Andrew F Clarke. Pilot study investigating the ability of an herbal composite to alleviate clinical signs of respiratory dysfunction in horses with recurrent airway obstruction. Canadian Journal of Veterinary Research.May,2007;71(2):145-151.

14. Mohammad Hossin Boskababy, Sahar Kiani, Hoda Azizi and Tahereh Khatami. Antittusive effect of cuminum Cyminum Linn. in guinea pigs. Natural product Radiance. 2006; Vol-5(4):266-269.

15. Lal.G and Meena.SS. Medicinal and Therapeutic Potential Of Seed Spices. Biomedical Journal Of Scientific \& Technical Research. June, 2018 ; Vol - 5 (4): 1 - 21.DO I : 10.26717 / BJSTR.2018.05.001240.

16. Mohammad M. Zarshenas, Mahmoodreza Morin, Soliman Mohammadi Samani, Peyman Petramfar. An Overview on Ajwain (Tracyspermum ammi L) Pharmacological Effects; Modern and Traditional . Journal of Natural Remedies. January,2014;vol-14(1):98-105

17. Eajazahmad Dar, Mehdi, Mushtaq ahmad, Faisal Nabi Bhat, Nazeer Hussain, Mansoor Hussain, Mohamed Amin Bhat, Nishat Hassan, Sabiya Asmat, Tahmina Mushtaq, Aziz M A and Fayaz Ahmad Bahar. Cumin: The Flavour of Indian Cuisines-History, Cultivation and Uses. Chemical Science Review and Letters.2019;8(29):129-135.

18. Alan Jiang.T. Health Benefits of Culinary Herbs and Spices. Jiang: Journal of AOAC International. March,2019; Vol-102(2):395-411. DOI: 10.5740/ jaoacint.18-0418.

19. Satyanand Tyagi, Patel Chirag, Dadarwal Poonam, Mangukia Dhruv, Sojitra Ishita, Zubair Khalid habu, Kumar Gupta, Kalpen N. Importance Of Garlic (AlliumSativum.L): An Exhaustive Review.Journal of Drug Discovery and Therapeutic. January,2013;1(4);23-27.

20. Igor Sobenin, Irina Andrianova, Elena Servers, Ljudmica Borodina, Vasily Karagodin, Alexander Orekhov. The Effects of Time -Released Garlic Powder Tablets On Acute Respiratory Diseases In Children. Medical and Health Science Journal. November, 2011;9:31-37. DOI:10.15208/ mhsj.2011.176.

21. Gebreselema Gebreyohannes, Mebrahtu Gebreyohannes. Medicinal Values of Garlic: Areview. International Journal Of Medicine and Medicine S c i e n ces. September,2013;Vol5(9):401-408. DOI:10.5897/ IJMMS2013.0960.

22. Elizabethh A, Townsend, Mathew E. Siviski and Charles W. Emala. Effect of Ginger and it's Constituents on Airway Smooth Muscle Relaxation and Calcium Regulation. American Journal of Respiratory Cell and Molecular Biology. Feburary,2013;48(2):157-163.doi:10.1165/ rcmb.2012-02310C.

23. Rajesh Kumar Mishra, Anil Kumar and Ashok Kumar. Pharmacological Activity of zingiber officinales Rosc. International Journal of Pharmaceutical And Chemical Sciences. January,2012;Vol_1(3):1073-1079. 
24. Ram A, Das M, Ahosh B. Curcumin Attenuates allergen-induced Airway Hyper responsiveness in Sensitized guinea pigs. Biological \& Pharmaceutical Bulletin. August, 2003; 26(7): 1021-1024. DOI:10.1248/bpb.26.1021.

25. Kohli K, Ali J, Ansari M I, Raheman Z. Curcumin: A Natural Anti inflammatory Agent .Indian Journal of pharmacology. June,2005;vol-37(3):141-147.

26. Aishwaryaa Balakrishnan. Therapeutic Uses of Peppermint A Review. Journal of Pharmaceutical Sciences and Research. July,2015;Vol-7(7):474-476.

27. Tamaoki.J, chiyotani.A, Sakai.A, Takomura.H and Konno.K. Short Report Effect of Menthol Vapour On Airway Hyper responsiveness in Patients With mild asthma. RespiratoryMedicine. August,1995;89(7):503-504.doi:10.1016/0954-6111 (95)90127-2.

28. Keith W. Singletary.Basil: A Brief Summary of Potential Health Benefits. NutritionToday. March,2018;53(2):92_97. DOI:10.1097/ NT.0000000000000267.

29. Khalidd Hussain Janna's,Irfan Hamid,Anwar-ulHas a n Gilan i, M. Im ran Qadir.spasmolytic ,Bronchodilator and Vasodilator Activities of Aqueous-Methanolic Extract of
Ocimum Basilicum Linn. Internation Journal of Agriculture and Biology. January,2014;Vol-16(2):321-327.

30. Dirgha Raj Joshi,Abinash Chandra Shrestha,Nisha Adhikari . A Review on Diversified use of the King of spices:Piper Nigrum(Black pepper). International Journal of PharmaceuticalSciencesand Research.October,2018;Vol-9(10):4089-4101.

31. Kankanam Gamage Chithramala Dissanayake, Waliwita Angoda Liyanage Chandra Siri Waliwita, Ruwan Priyantha Liyanage. A Review on Medicinal Uses of Zingiber officinale(Ginger). International Journal Of $\mathrm{Health} \mathrm{Sciences}$ and Research.June,2020;Vol-10(6):142-148.

32. COVID-19: Guidelines for pharmacists and the pharmacy workforce. Updated on 26, march-2020By FIP Health advisory-International Pharmaceutical federationhttps://www.fip.org

33. Nilima Thombre, Priyanka. S Ahire, Tidke Sonali, Sanjay Kshirsagar.Review : Herbals As Bronchodilator. Indian Journal of Drugs. 2019; 7(2): 43-48.

34. Guidelines for siddha practioner covid-19.Updated on $13^{\text {th }}$ April 2020 by Govt.of India -Ministry of AYUSH https://www.ayush.gov.in. 